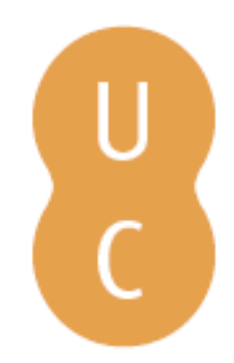

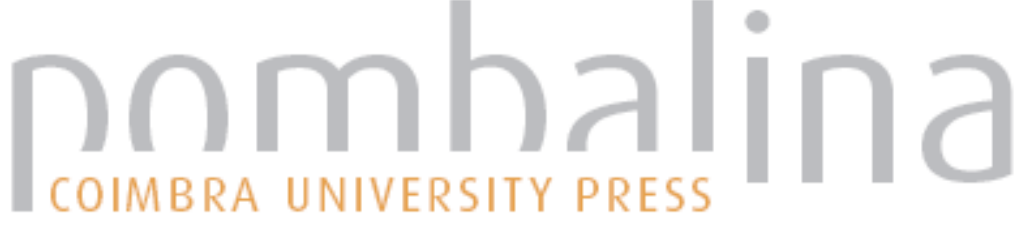

\section{Metafísica e construtivismo}

Autor(es): $\quad$ Pires, Edmundo Balsemão

Publicado por: Imprensa da Universidade de Coimbra

URL

persistente: URI:http://hdl.handle.net/10316.2/32238

DOI: $\quad$ DOI:http://dx.doi.org/10.14195/978-989-26-0361-2_9

Accessed : $\quad$ 26-Apr-2023 14:35:33

A navegação consulta e descarregamento dos títulos inseridos nas Bibliotecas Digitais UC Digitalis, UC Pombalina e UC Impactum, pressupõem a aceitação plena e sem reservas dos Termos e Condições de Uso destas Bibliotecas Digitais, disponíveis em https://digitalis.uc.pt/pt-pt/termos.

Conforme exposto nos referidos Termos e Condições de Uso, o descarregamento de títulos de acesso restrito requer uma licença válida de autorização devendo o utilizador aceder ao(s) documento(s) a partir de um endereço de IP da instituição detentora da supramencionada licença.

Ao utilizador é apenas permitido o descarregamento para uso pessoal, pelo que o emprego do(s) título(s) descarregado(s) para outro fim, designadamente comercial, carece de autorização do respetivo autor ou editor da obra.

Na medida em que todas as obras da UC Digitalis se encontram protegidas pelo Código do Direito de Autor e Direitos Conexos e demais legislação aplicável, toda a cópia, parcial ou total, deste documento, nos casos em que é legalmente admitida, deverá conter ou fazer-se acompanhar por este aviso.

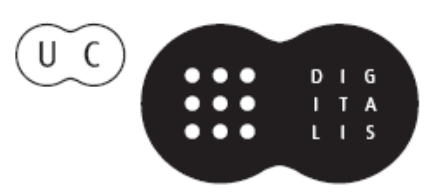


Diogo Ferrer

Coordenação

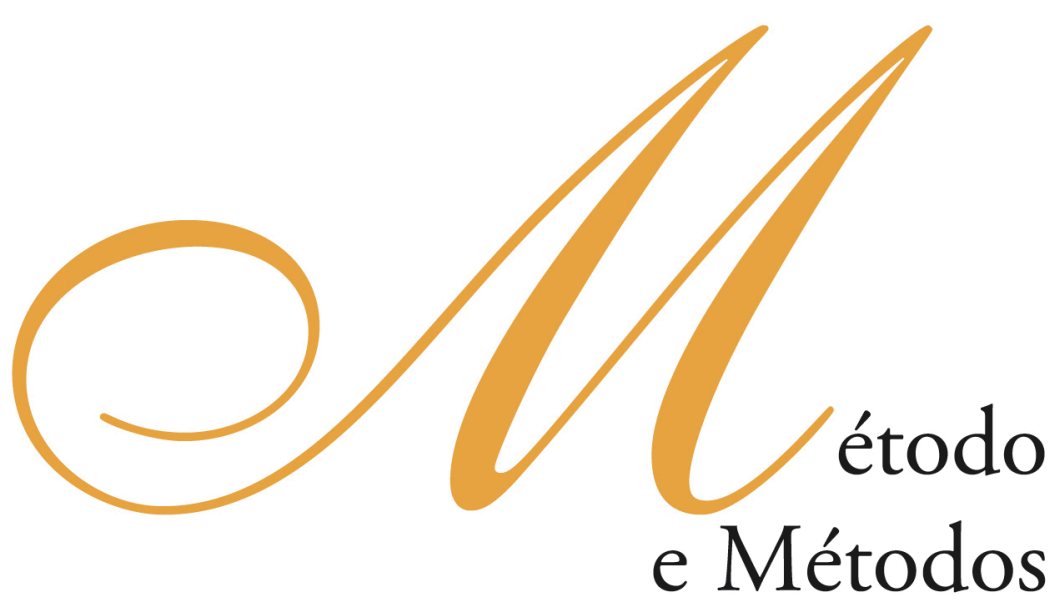

do Pensamento Filosófico 


\section{COORDENAÇÃO EDITORIAL \\ Imprensa da Universidade de Coimbra}

URL: http//www.imp.uc.pt

\section{CONCEPÇÃO GRÁFICA}

António Barros

PRÉ-IMPRESSÃO

Victor Hugo Fernandes

EXECUÇÃO GRÁFICA

Inova - Artes gráficas

ISBN

989-8074-02-7

DEPÓSITO LEGAL

$257236 / 07$

(C) Março 2007, Imprensa da Universidade de Coimbra

OBRA PUBLICADA COM O APOIO DE:

Centro de Estudos Clássicos e Humanísticos

FCT Fundação para a Ciência e a Tecnologia MINISTÉRIO DA CIÊNCIA E DA TECNOLOGIA 
Diogo Ferrer

Coordenação

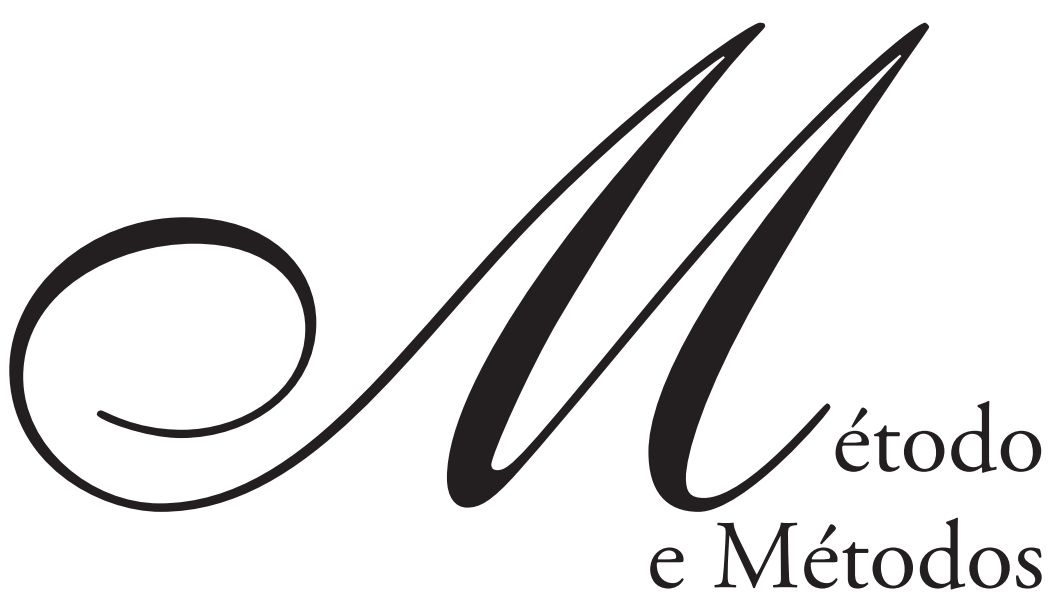

do Pensamento Filosófico

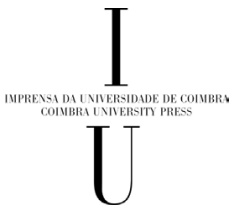

- COIMBRA 2007 



\section{Metafísica e Construtivismo}

5.6 Kognitive Prozesse schaffen Beschreibungen der Umwelt, $d . h$. Information über die Umwelt.

6. Die Umwelt enthält keine Information. Die Umwelt ist, wie sie ist.

(H. von Foerster, "Gedanken und Bemerkungen über Kognition»)

\section{Metafísica}

A grande ambição da tradição metafísica mais recuada consistiu em poder incluir o saber humano e os observadores do mundo no movimento mais geral do ser e ao alcance da sua causalidade.

Se pusermos de parte o cepticismo antigo e os seus tópicos, e o que podemos identificar como núcleo doutrinal na ironia socrática, só verdadeiramente na feição moderna desta tradição metafísica se revelou com clareza o problema de saber se a causalidade metafísica deve incluir o observador do mundo do lado do mundo e da causalidade anónima do ser ou se é nas observações dos observadores que o próprio mundo tem de se significar e se, por isso, a causalidade metafísica não é, afinal, ela mesma, uma parte da causalidade descoberta por observadores particulares nas suas actividades quotidianas ou na descoberta científica.

Se a resposta for neste último sentido, seremos, de um modo ou de outro, "Construtivistas», e aos problemas da observação do mundo temos de dar 
respostas éticas fundadas no conceito de responsabilidade do observador pelo modo como atribui sentido às suas descrições, como pretendeu $\mathrm{H}$. von Foerster.

Tentarei dar resposta a esta mesma questão mediante uma abordagem que dividirei em duas partes.

Nesta primeira parte vou sumariar as dificuldades com que se defronta a tradição metafísica na filosofia moderna quando enfrenta dois problemas principais: o problema da enorme diversidade de construções e discursos sobre o mundo e a constatação de que são muitas vezes contraditórios, não existindo qualquer via de acesso directa à chamada «realidade»; o problema da re-entrada da observação dentro da observação e o facto de só aqui estarmos perante toda a riqueza ontológica, não obstante a re-entrada ser o fruto de actos voluntários, livres, de observadores e não determinações ontológicas a que darei mais atenção na segunda parte.

A tradição clássica representada pelo tipo gnosiológico do «realismo ingénuo" partia forçosamente do isolamento do observador em relação ao objecto observado e toda a sua visão da ideia de substância supunha as ideias de existência exterior e de independência. Mas na medida em que a independência de alguma coisa em relação à observação era um postulado fundamental, a ideia de inerência desenvolveu-se paralelamente à própria ideia de substância, para poder dar conta de que as notas que as observações iam isolando da coisa correspondiam a dimensões da própria coisa e com ela faziam uma unidade.

O conceito de substância da tradição clássica sofre uma metamorfose no mundo moderno no sentido de obedecer às novas necessidades de explicação da natureza da Física moderna.

A definição cartesiana de substância como «aquilo que não necessita de nenhuma outra coisa para existir ou ser concebida» levou Descartes ao dualismo substancialista, que é um modo de generalizar, do ponto de vista metafísico, a distinção entre as duas faces da observação de que a ciência moderna tem de partir e que ela pressupõe. 
Na ideia cartesiana da substância é negada à extensão a possibilidade de desenvolver qualquer forma de auto-percepção, na medida em que o atributo do pensamento só pode ser atribuído à substância pensante e só esta última é dotada de auto-consciência. Neste sentido, aquilo que o pensamento pode 203 isolar da extensão são apenas aquelas notas que correspondem ao que é extenso e nunca se podem observar na extensão notas do pensamento. Reciprocamente, a extensão não é dotada de pensamento, logo as coisas que nós observamos como regiões do mundo físico não pensam, não sentem e muito menos são dotadas de auto-reflexão.

Com a grande excepção de Espinosa, na metamorfose moderna da herança clássica o dualismo substancial foi o meio de que se serviu a filosofia para exprimir a diferença entre as duas faces da operação de observação que a ciência moderna exige.

O dualismo pensamento-extensão foi então várias vezes traduzido no dualismo sujeito-objecto e neste último é fácil identificar o conceito de observação da ciência moderna e a sua necessidade de estabelecer distinções apropriadas entre coisa (mundo das coisas) e mente (ou observador e aparelhos de observação).

O mundo moderno e a filosofia moderna com ele criavam então a metafísica apropriada ao seu observador privilegiado - o cientista.

Em uma determinada fase da auto-consciência da ciência moderna a ideia de uma realidade independente das descrições científicas foi uma exigência ingénua dos próprios cientistas que em vez de contestarem essa noção a fortaleceram, pois julgaram que poderiam legitimar as suas concepções com a referência a um critério de verdade inabalável, o da verificação experimental, fundado na ideia de que as coisas eram de determinada forma fora do espírito dos observadores. Isto contribuiu para que a metafísica da substância e da relação de inerência se consolidasse, mesmo sem que houvesse qualquer crença metafísica muito forte, desta vez em associação com uma teoria sobre as bases sensoriais da ciência e da experiência científica. 
Do «realismo ingénuo» ao Positivismo podemos apreciar o percurso de uma concepção da representação que está profundamente associada com a ideia de reprodução por imagens mentais de conteúdos independentes das nossas actividades, existentes num mundo também ele indiferente à actividade humana e às suas distinções operatórias. É neste sentido que não deve parecer estranho que as teorias do conhecimento baseadas na noção da representação-imagem tenham mantido a sua dose de metafísica, mesmo que inconsciente.

Sem quebrar com o conceito de substância, na filosofia moderna é com Espinosa que vamos situar uma perspectiva já afastada desta visão cartesiana, precisamente porque agora partimos de um nexo substancial que se dá no interior da única substância, e em que a admissão do dualismo, por conseguinte, não é nem integral nem fundadora. O dualismo não é uma doutrina ontológica integral, mas é, antes, um esquema de entendimento das formas de expressão da única substância.

Se na sua faceta finita e limitada o corpo não possui pensamento e se a extensão não tem auto-consciência sabemos, contudo, que essa convergência entre extensão e pensamento e a possibilidade de uma transgressão de um na direcção do outro se exprime na fonte produtora de todo o Real que é Deus.

Com Hume e a sua crítica fenomenista da substância situamo-nos num caminho praticamente inverso: é aquele que parte dos actos da consciência como os únicos pontos de apoio para ter algum acesso ao que se chama realidade e segundo o qual tudo deve poder reduzir-se a estados e actos de consciência com os seus conteúdos.

Na obra de D. Hume já era possível apercebermo-nos do carácter indevido da passagem de actos de consciência particulares para a concepção de uma substância entendida como suporte desses actos. Aqui, é possível tomar contacto com uma visão não-substancialista da realidade quer no que se refere à realidade material quer naquilo que diz respeito à mente e ao sujeito. 
O bi-substancialismo cartesiano está em questão, mas também toda a tradição em que assentava a própria noção de substância como coisa real dotada de certas características a que pertenciam outras coisas que dela se derivavam, por meio da relação de inerência.

Com Espinosa e Hume vemos nascer na filosofia moderna duas orientações sobre o tema da substância e sobre as condições do conhecimento, e ambas estão em relação com duas poderosas críticas ao conceito tradicional de substância.

A partir de Espinosa o monismo da única substância vai traduzir-se numa filosofia da unidade de acordo com a qual é a consciência que se deve entender como uma modificação desse uno que é todo, e em que à consciência e ao sujeito não é atribuído um papel privilegiado na génese da «realidade».

Não é por acaso que a época de ouro do pensamento da unidade no Idealismo Alemão de Schelling e Hölderlin a F. Schlegel e a Hegel é um período caracterizado por uma intensa actividade de recepção da obra de Espinosa.

O caminho que leva de Espinosa aos românticos, a Hegel e ao materialismo foi já diversas vezes investigado e revisitado.

O caminho de Hume até à fenomenologia é também fácil de percorrer e tem os seus temas já assinalados na investigação especializada.

Com Hegel e na história do materialismo podia já encontrar-se a noção de um saber e reflexão atribuídos à realidade objectiva, como «espírito objectivo", numa perspectiva que punha seriamente em causa o dualismo cartesiano e a separação metafísica das substâncias, como a que ocorre entre pensamento e extensão corpórea. A grande tentação que percorre o pensamento hegeliano é a de laboriosamente ensaiar uma resposta às dificuldades da tradição metafísica dentro da linguagem dessa tradição, nomeadamente naquilo que se refere à reposição da unidade entre subjectividade e objectividade, quer como unidade objectiva da diferença entre sujeito e objecto quer como unidade subjectiva da diferença entre 
sujeito e objecto. Ora, é precisamente com Hegel que nos apercebemos melhor como uma das grandes dificuldades está na tradução de um dos membros do dualismo no seu oposto e a possibilidade de recuperar a ambos numa unidade integradora. G. Günther explicou o significado da Lógica hegeliana nesta perspectiva e mostrou como aqui se preparou muitas das questões debatidas na teoria da cibernética(1).

Mas independentemente da conturbada história do conceito de substância e independentemente do facto de ao longo da história da filosofia suspeitarmos de uma «inquietante estranheza» relativamente ao modo como o homem comum e o cientista formado na física moderna se pareciam comprazer com a noção imediata de objectividade, a metafísica da ciência moderna, a noção de objecto como dado imediato e o método científico fortaleceram-se mutuamente. Desta aliança temos testemunho na História do positivismo.

Actualmente, a consciência metodológica da filosofia atravessa uma profunda crise em virtude da transformação do modelo de observação da ciência moderna, sob o impacto da nova construção física, biológica e cibernética da realidade, que já nada tem de semelhante à física dos séculos XVII e XVIII.

A noção contemporânea de máquinas inteligentes capazes de aprender, a ideia de auto-reflexão das máquinas e mais propriamente a noção de causalidade circular, de controlo sobre os próprios estados, e de feedback trouxe consigo a consequência de alcance muito vasto segundo a qual a observação não é um predicado exclusivo dos estados de consciência, não é um resultado exclusivo do funcionamento do psiquismo humano, mas pode ocorrer na própria matéria, como um fenómeno produzido artificialmente ${ }^{(2)}$.

(1) Cf. G. Günther, «Der Tod des Idealismus und die letzte Mythologie» unveröffentlichtes Manuskript im Besitz der Staatsbibliothek Preußischer Kulturbesitz, Berlin. Versão editada por R. Kaehr para uso interno do ICS in http://www.thinkartlab.com/pkl/tod-ideal.htm, p. 2.

(2) A doutrina de G. Günther sobre o significado ontológico da cibernética assenta numa determinada reconstrução da unidade sujeito-objecto, de que a Dialéctica de Hegel e alguns autores do chamado "Idealismo Alemão" deram modelos interpretativos. O conceito da dialéctica como "Realproze $\beta$ " que o filósofo desenvolve no seu escrito sobre «A Morte do Idealismo», na 
Nos conceitos de forma e distinção e na diferença entre sistema e meio ambiente, típica da teoria dos sistemas, revemos a necessidade de manter uma dualidade que deriva não já da visão de coisas independentes umas das outras e separadas da mente que as constrói segunda uma determinada relação (3).

A cibernética trouxe consigo a ideia de que a justificação da imagem mais completa da realidade não se pode obter nem com a teoria pacóvia sobre a constituição das coisas fora da mente, com uma determinada disposição, nem com base na separação em dois reinos ontológicos do observador e do mundo observado(4).

Todas as diferenças devem poder ser explicadas pelo exercício de operações e, neste caso em particular, devem poder ser explicadas pela operação de observação.

Considerada como operação de um tipo particular, a observação não é, deste modo, um acto que se vem sobrepor a estados de coisas que já têm no seu fundamento a substância, que indiscutivelmente estaria aí e seria o suporte dos fenómenos no mundo(5).

continuação de trabalhos anteriores, desemboca na ideia de centros subjectivos (Ichzentrum) na própria realidade, como domínios da distribuição da unidade dialéctica de sujeito-objecto. Trata-se de «lugares ontológicos» dotados simultaneamente de objectividade e reflexão, ou seja, precisamente aquela unidade requerida para poder reconhecer o âmbito ontologicamente adequado das máquinas inteligentes. O percurso a que nos convida G. Günther é para o caminho que leva de Hegel e da dialéctica até a uma Filosofia da Técnica, cujo centro está numa justa ideia do papel da cibernética na civilização actual. Cf Idem, «Der Tod des Idealismus und die letzte Mythologie» unveröffentlichtes Manuskript im Besitz der Staatsbibliothek Preußischer Kulturbesitz, Berlin. Versão editada por R. Kaehr para uso interno do ICS in http://www. thinkartlab.com/pkl/tod-ideal.htm, p. 21.

(3) Sobre esta questão remeto o leitor para o texto de N. Luhmann sobre a comunicação ecológica, onde a respeito de precisões conceptuais sobre o conceito de "Welt" e "Umwelt" escrevia o sociólogo: Es muß eine Systemgrenze gezogen werden, damit die Welt die Möglichkeit gewinnt, sich selbst zu beobachten. Anderenfalls gäbe es nur pure Faktizität (N. Luhmann, Ökologische Kommunikation, Opladen, $1990^{3}$, p. 45; cf. P. Fuchs, Der Sinn der Beobachtung. Begriffliche Untersuchungen, Weilerswist, 2004, pp. 25-30; 39-51.

(4) Cf. E. von Glasersfeld, "Konstruktion der Wirklichkeit und des Begriffs der Objektivität» in H. Gumin / H. Meier (Hrsg.), Einführung in den Konstruktivismus, München, $2002^{6}$, pp. 9-39, 31 e ss.

(5) E. von Glasersfeld descreve a visão construtivista da realidade como uma visão fundada nas vivências e na acção dos observadores, ou seja, como uma perspectiva instrumental, 
Não só os estados de coisas não se podem explicar por uma base substancial que seria a causa metafísica desses fenómenos e acontecimentos, como as próprias observações não se podem tomar como momentos de uma série substancial, que seria a série psíquica, e, com isso, seriam independentes do próprio conteúdo ou região semântica da observação.

A tese construtivista consiste, primeiramente, na ideia de que a observação é uma operação, que transcende os sistemas psíquicos, e pode dar-se também em animais e máquinas. Uma tal operação é feita de distinções.

Uma distinção designa uma forma com duas faces de valor diferente e vai surgir aí onde existia apenas um espaço uniforme, indistinto, sem marcas de relevância.

\section{Construtivismo}

Nesta segunda parte, antes de prosseguir convém referir que o conceito comum de "construtivismo" é vasto e vai desde posições teóricas relativas ao valor do conhecimento matemático até à Arte, à Pedagogia, Psicologia e teorias da aprendizagem (J. Piaget), à Linguística e à História.

Partamos do princípio muito genérico de que a Ontologia consiste na investigação do ser e das suas modalidades.

A tese segundo a qual todo o real é fruto de construção e não são possíveis ou não possuem fundamento aquelas asserções sobre o que é o real em si mesmo, corresponde a uma afirmação céptica sobre o alcance do conhecimento humano que, no mínimo, implica uma suspensão céptica do juízo em metafísica, relativamente ao que as coisas são em si mesmas.

Não é esta, exactamente, a tese "construtivista", que tem outro tipo de preocupações no seu horizonte.

adaptativa e evolutiva da "construção» da realidade em oposição à perspectiva estática da tradição substancialista. Cf. Idem, Ibid., pp. 29-31. 
Em geral, aquela "suspensão" pode ter dois significados: ou com ela nos referimos a uma concepção da própria realidade que se identifica com a tese de que o ser é um vazio diversamente preenchido com as nossas construções do real ou, então, estamo-nos a referir a uma tese agnóstica que dispensa qualquer afirmação sobre o ser e se prefere concentrar nas estruturas da nossa experiência, da qual partimos para a organização do nosso saber do mundo, pois se não sabemos o que são as coisas, pelo menos podemos descrever como conhecemos a realidade.

$\mathrm{O}$ "construtivismo" conhece posições que oscilam desde a primeira posição de tipo marcadamente ontológico até às versões mais próximas deste agnosticismo metafísico.

No entanto, nas versões do «construtivismo radical» de $\mathrm{H}$. von Foerster a $\mathrm{H}$. Maturana(6), que aqui nos vão importar mais, a questão que se nos coloca é a de saber se devemos ou não atribuir uma realidade independente, exterior às nossas actividades e distinções operatórias, aos conteúdos das nossas construções e se, afinal, como pretendeu toda uma tradição, as observações, com que se tece o conhecimento, resultam de representações-imagens.

Nos textos dos construtivistas encontramos muitas vezes um estilo de argumentação em que são confundidas as diversas facetas do problema da relação entre saber e realidade, como o problema da substância e da causalidade metafísica, o da objectividade do conhecimento, o problema da concepção do conhecimento como reprodução ou retrato da realidade dada como garantida, ou mesmo o problema da génese do conceito de realidade.

Para que o questionamento construtivista seja aqui levado a sério e não se torne em mero problema verbal, é importante definir conceitos e, desde logo, o conceito de realidade objectiva.

(6) Cf. para uma apreciação geral: E. von Glasersfeld, "Kleine Geschichte des Konstruktivismus»in A. Müller / K. H. Müller / F. Stadler (Hrsg.), Konstruktivismus und Kognitionswissenschaft. Kulturelle Wurzeln und Ergebnisse. Heinz von Foerster gewidmet, Wien - New York, 2001, pp. 53-62. 
A primeira parte na nossa questão deve consistir no isolamento do problema da objectividade.

Se por objectividade nós entendermos o modo como nos actos de consciência resulta a posição de uma coisa ou de coisas "fora" desses actos de consciência, ou em geral da mente, com uma existência independente, então essa coisa é concebida como coisa "objectiva» e, naturalmente, se pretendermos dar todo o significado à presunção da objectividade, essa coisa tem, também, de ser concebida como uma coisa real, quer dizer, como algo que não está dependente da fantasia ou da combinação imaginativa de coisas previamente formadas e retidas pela memória de um sujeito a sós com o seu fluxo de consciência.

Assim, à luz deste sentido do «real», a concepção de uma coisa objectiva inclui a concepção dessa coisa como coisa real.

Mas temos de ser claros quando afirmamos que esta inclusão da realidade na objectividade está dependente da forma como nos actos de consciência nós concebemos o conteúdo desses actos de consciência, a sua região semântica. Neste sentido particular, só no que Husserl chamou visada intencional é possível entender a formação da objectividade.

No entanto, a objectividade é gerada na forma da consciência mas sempre na medida em que a consciência se relaciona com a acção. A objectividade é um predicado da consciência-acção e não apenas da consciência isoladamente, aspecto que a Fenomenologia não esclareceu em todo o seu alcance ${ }^{(7)}$.

Se partirmos isoladamente da intencionalidade da consciência polarizada em redor dos seus conteúdos não entendemos de onde vem o valor de objectividade que atribuímos a certos conteúdos e não a outros. Só a

(7) A este propósito o leitor pode esclarecer aspectos da relação entre a posição do construtivismo e a fenomenologia e ajuizar sobre o alcance do juízo sobre o "fracasso" do projecto de Husserl a partir da obra de F. Varela, E. Thompson e E. Rosch, The Embodied Mind: F. Varela / E. Thompson / E. Rosch, Der mittlere Weg der Erkenntnis. Der Brückenschlag zwischen wissenschaftlicher Theorie und menschlicher Erfahrung, (trad.), Bern, München, Wien, 1991, pp. 38 e ss. Os autores consideram que a principal razão do fracasso do projecto de Husserl se deveu à falta de atenção ao aspecto pragmático da construção da realidade e, consequentemente, da teoria. 
articulação permanente entre fluxo da consciência e acção, na própria vivência, permite associar o valor de objectividade que emprestamos a certas representações com as formas de adaptação de um determinado sujeito da vida intencional ao mundo. É daqui que resulta a ideia de acordo com a qual as noções de objectividade e de realidade estão dependentes do conceito de resistência ao poder da vontade de um sujeito ou de sujeitos. Todavia, a resistência é uma noção que depende da relação de uma acção com outra acção possível. Verdadeiramente, não se contém logicamente na ideia de resistência o conceito de uma realidade prefigurada com estes e aqueles predicados, fora do ciclo de acções de sujeitos $(8)$.

Depois de alguns séculos de crítica da noção de substância, a crença na existência de fundamentos da realidade material e da mente pode identificar-se com um preconceito de gente iletrada. Mas nem por isso ficou mais bem esclarecida a base do conceito comum de realidade objectiva e, sobretudo, de que modo extraímos dos actos de consciência a posição do que quer que seja como coisa objectiva, real e independente dos actos subjectivos de atribuição de sentido e ficamos também sem saber se há legitimidade para isso.

Se a disposição dos actos da consciência nos leva a conceber este ou aquele elemento de uma dada região semântica como elemento objectivo, então com esta noção é possível compreender esse elemento objectivo, ao mesmo tempo como elemento real. Os conceitos de objectividade e de realidade são interpermutáveis, pois não conseguimos visar uma coisa objectivamente sem presumir em relação a essa coisa a nota da sua existência real.

O conceito de realidade aqui opõe-se ao conceito do possível, mas igualmente ao conceito do irreal e do imaginário. O conceito de um ser possível é simplesmente equivalente ao conceito de um acto de consciência

(8) Cf. Idem, Ibid., in loc. cit., p. 31: Die Welt der objektiven Hindernisse, der ontischen Schranken, zwischen denen wir handeln, erleben und zuweilen unsere Ziele erreichen, bleibt grundsätzlich unzugänglich und unbeschreibbar. 
em cuja região semântica não conseguimos descobrir a objectividade. Deste modo, e de acordo com a nossa equivalência entre objectividade e realidade, um ser possível é tudo aquilo a que não atribuímos uma independência em relação a nós próprios.

Na medida em que uma coisa objectiva e real deve, também ela, poder nascer na relação com um dado acto de consciência, dizemos que a realidade resulta de uma determinada modificação da possibilidade e a modificação do possível no actual e do actual no «objectivo» é sempre algo de móvel e fluído.

As diferenças modais do real e do possível são diferenças que não resultam da constituição das coisas e do mundo que nos rodeia mas são distinções operadas na relação entre os actos de consciência, a acção e a região semântica da acção e da consciência.

$\mathrm{Na}$ história do construtivismo este conjunto de problemas foi objecto de atenção no quadro do conceito de observação.

Já no século XIX, nas suas investigações sobre a especificidade dos órgãos sensoriais, a multiplicidade de órgãos e a especialização sensorial, J. Müller chamava a atenção para a ideia, mais tarde amadurecida, segundo a qual o cérebro tem um funcionamento auto-referencial e, por conseguinte, entre o cérebro e a chamada "realidade» não há um contacto feito de portas e janelas abertas, com base num modelo de troca directa em um espaço homogéneo. As investigações de J. Müller podem hoje ser interpretadas como antecipações da ideia de que a especificidade sensorial representa a regra de uma múltipla codificação da experiência, não sendo possível um único código constitutivo do que chamamos «realidade»(9).

No ano de 2003 foram finalmente publicados todos os protocolos das célebres J. Macy Conferences, ocorridas entre 1946 e 1953, sob os auspícios da

(9) Recentemente, no projecto de pesquisa de G. Roth no âmbito da relação entre neurobiologia e teoria da representação, voltou-se a questionar muitos dos problemas formulados por J. Müller, Cf. G. Roth, "We are constructs ourselves» in B. Poerksen, The Certainty of Uncertainty. Dialogues introducing Constructivism, (trad), Exeter, 2004, pp. 109-132. 
Academia das Ciências de Nova Iorque, que marcavam o nascimento de uma ciência decisiva para a formação do construtivismo: a cibernética(10).

No quadro das Macy Conferences, H. von Foerster havia desenvolvido o esquisso da sua teoria da memória no texto "Quantum Mechanical Theory of Memory» (1949) (11).

Abstraindo dos pormenores da complexa descrição da memória deste trabalho, o que o autor pretendia demonstrar era a tese geral segundo a qual a percepção e a retenção de determinados traços mnésicos dos dados dos órgãos dos sentidos se desenvolve como um processo selectivo e nunca ocorre independentemente da capacidade selectiva de um sujeito(12). Sem selecção não existiria memória nem traços mnésicos. Por conseguinte, a mente não pode ser compreendida como tabula rasa ou superfície passiva para inscrições sucessivas de acontecimentos, mas resulta de um cálculo(13).

Correndo o risco de sumariar excessivamente vou isolar algumas ideias que quero reter da obra de H. von Foerster.

1. Antes de tudo, a ideia de que uma parte significativa da tradição gnosiológica assentou na teoria errada do conhecimento como quadro figurativo da realidade, em que esta é tomada como variável independente, existente fora da linguagem e fora das descrições dos observadores.

2. O princípio segundo o qual o conhecimento tem lugar em descrições e essas descrições em formas discursivas dependentes de distinções que os

(10) C. Pias (Hrsg.), Cybernetics - Kybernetik. The Macy-Conferences 1946-1953. Transactions/Protokolle, 2 Bd., Zürich, Berlin, 2003.

(11) H. von Foerster, "Quantum Mechanical Theory of Memory» in C. Pias (Hrsg.), Cybernetics - Kybernetik. The Macy-Conferences 1946-1953. Transactions / Protokolle, 2 Bd., Zürich, Berlin, 2003, op. cit., Bd. 1, pp. 98-121.

(12) Aplicando à memória o princípio da mecânica quântica segundo o qual não existe nenhum estado absolutamente estável da matéria, H. von Foerster desenvolve uma fenomenologia do dinamismo da memória apoiada em seis aspectos, a saber: 1. a impressão elementar; 2. o portador da impressão elementar; 3. a decaída dos portadores; 4. a memorização como um poder; 5. a transmissão como um processo; 6. a transmissão como uma selecção. Cf. Idem, Ibid., p. 106.

(13) Idem, Ibid., p. 114. 
sistemas de signos de uma linguagem validam e reproduzem com a finalidade da comunicação. Esta ideia é comum à concepção de H. Maturana.

3. Finalmente, a ideia de que nunca podemos saber o que é uma coisa totalmente situada fora da observação e do sistema de distinções dos observadores, como "realidade objectiva» e, por isso, fica-nos vedado um critério definitivo, e independente do quadro das observações, relativo à separação entre realidade e ilusão(14).

Para as Macy Conferences G. Bateson tinha preparado uma contribuição com o título "A posição do humor na Comunicação Humana" (1952) (15). Neste trabalho, o riso, o orgasmo e a tristeza são entendidos como traços de comportamento característicos do homo sapiens, mas também formas de comunicação ilustrativas de algumas propriedades que interessaram o autor de uma forma especial. Dos três comportamentos reteve G. Bateson o riso.

Para exemplificar com o riso G. Bateson recorreu à experiência comunicativa da anedota.

Nas anedotas o riso aparece na modalidade de um acto compulsivo em certo grau, mas igualmente como um comportamento no qual se revela a inteligência humana(16)

A anedota é um tipo de curta narrativa que trabalha intencionalmente com a diferença entre informação de background e informação focal. Quando se dá o cruzamento entre um e outro tipo de informação, quando ambos se sobrepõem, forma-se o equivalente a um paradoxo, que pode ser então apreendido como a fonte ou motivo do riso(17)

(14) Alguns dos problemas formulados no seu trabalho sobre a memória reapareceram e reformularam-se num texto mais recente. Cf. H. von Foerster, "Gedanken und Bemerkungen über Kognition" in Idem, Idem, Wissen und Gewissen. Versuch einer Brücke, Frankfurt/M., 1993, pp. 77-102.

(15) G. Bateson, "The Position of Humor in Human Communication" in C. Pias (Hrsg.), Cybernetics - Kybernetik. The Macy-Conferences 1946-1953. Transactions / Protokolle, op. cit., Bd. 1, pp. 541-574.

(16) Idem, Ibid., p. 542.

(17) When the point of a joke is reached, suddenly this background material is brought into attention and a paradox, or something like it is touched off. A circuit of contradictory notions is completed (Idem, Ibid., p. 542). 
A relação que aqui G. Bateson tipificou foi aquela que se dá entre figura e fundo. Entre o que estava em background e o que era o tema realçado há uma substituição, o que parecia ignorado, virtual, potencial, torna-se no centro focal da atenção. Ainda segundo ele, algo de semelhante ocorre na tragédia clássica e na ironia. Mas a sua tese consiste mais particularmente na afirmação de que entre figura e fundo se pode sempre dar uma interpenetração num continuum de experiência, sendo exactamente isso que assegura que o riso e a ironia possam associar-se à vida quotidiana e a loucura ao comportamento padronizado. A anedota, a ironia e os paradoxos têm em comum o facto de os três reverterem as posições relativas de fundo e figura. Esta possibilidade de reversibilidade e inversão de um dos aspectos no outro é qualquer coisa que experimentamos na nossa vida diária, o que levou um dos intervenientes da conferência a dizer, muito profundamente, que «a vida parece ser uma sequência de anedotas, cujo humor nós frequentemente não reconhecemos»(18).

As considerações de G. Bateson desde este período levaram a três ideias fundamentais, depois desenvolvidas nos trabalhos de P. Watzlawick, que passariam a estar no centro da atitude construtivista e que devemos associar às três outras ideias que encontramos na obra de H. von Foerster.

1. Toda a comunicação quotidiana implica paradoxos e a tentativa de escapar deles mediante soluções como a da teoria russelliana dos tipos é frágil. A descoberta de alguns paradoxos e a possibilidade de os eliminar implica comunicar sobre a comunicação.

2. A comunicação sobre a comunicação pode ser revertível em observação de observações.

3. Uma parte significativa dos paradoxos que emergem em situações comunicativas na vida quotidiana são paradoxos de auto-referência em que os observadores estão incluídos nas observações ou em que as comunicações comunicam sobre elas próprias ou supõem essa comunicação lateral ou

(18) Idem, Ibid., p. 550. 
implícita. Isto quer dizer que na comunicação assim como na observação nós estamos situados perante formas de auto-referência. A ontologia baseada no realismo ingénuo depende largamente do paradoxo que consiste em descrever na forma da coisa «independente» e "exterior» aquelas distinções que só são operadas na observação por observadores, como se não existisse esta mesma dependência em relação à perspectiva de quem observa.

Mais recentemente, quando N. Luhmann redescobriu a obra do psicólogo gestaltista F. Heider e o seu contributo para a diferenciação entre meio e forma as questões que G. Bateson sugeria com a sua diferença entre fundo e figura, a propósito da geração de paradoxos no discurso do humor e da ironia, tornaram-se ainda mais acutilantes.

O próprio ponto de partida do construtivismo não se pode assumir, sem contradição, como um ponto de partida objectivo, fixo, indiscutível pois não se refere ao modo como as coisas são na realidade fora de nós.

O discurso do construtivista terá de ser o de alguém que parte do saber e do discurso como fruto de um sistema de diferenças em permanente oscilação interna, em que o meio é sempre meio para novas formas, do mesmo modo que o fundo permite sempre o surgimento de novas figuras que nascem do fundo para logo nele se dissolverem.

É por isso que o construtivismo se justifica a ele mesmo como uma concepção da actividade científica, para a qual o princípio contrário, que parte da admissão de um mundo independente de nós e estruturado de determinada forma fora das observações e respectivas descrições não é muito fecunda e provavelmente trava o progresso da ciência e a formação de novas hipóteses.

É mesmo, muito possivelmente, um princípio adverso ao que é desejado para a metodologia científica.

O que G. Bateson, P. Watzlawick, H. von Foerster e, na segunda geração, H. Maturana tentaram mostrar foi que o princípio de uma realidade objectiva, independente das descrições dos observadores e das relações entre eles no meio da linguagem, é pouco instrutiva e pouco fecunda para o desenvolvimento da ciência. 
H. Maturana identifica na noção tradicional de objectividade a tese segundo a qual o mundo só pode ser concebido como um universo independente do observador.

É a esta ideia convencional que ele chama "objectividade sem parêntesis».

Diz mesmo que por esta «objectividade sem parêntesis» se devem entender as coisas enquanto elas têm uma existência fora da mente com os predicados que nós lhes atribuímos mediante uma projecção dos actos de consciência nos seus correlatos.

Nesta visão de uma realidade independente se contém o que vulgarmente chamamos universo, na acepção também habitual de um conjunto de coisas que existem independentemente.

Nos seus trabalhos, que seguem de perto a herança de H. von Foerster, H. Maturana separa-se da tradição substancialista de pensamento, que parte da existência de coisas fora da consciência, mas não destrói a coerência de um conceito de objectividade operatória, por exemplo.

Nem todos os conceitos de objectividade implicam a admissão dos postulados da tradição substancialista. Se isso acontecesse a crítica da independência metafísica das coisas implicaria a crítica de todo o tipo de realidade.

Esta correcção é importante se quisermos conceder alguma densidade ao conceito de "domínio da existência», que H. Maturana pretendeu substituir ao conceito substancialista de objectividade em um trabalho, datado de 1990, com o título «The biological foundations of Self Consciousness and the Physical Domain of Existence»(19).

O "domínio da existência» é um domínio «objectivo» porque não pode reduzir-se à consciência subjectiva de um sujeito isolado ou a um fluxo de consciência, na acepção tradicional, mas não é uma substância, no sentido tradicional, porque não subjaz às diferentes coisas que existem como uma

(19) H. Maturana, "The Biological Foundations of Self Counsciousness and the Physical Domain of Existence» in AA. VV., Beobachter. Konvergenz der Erkenntnistheorien? München, 1990, pp. 47-118. 
razão de ser independente e exterior e segundo a lógica própria das relações de inerência.

É este âmbito que ele pretende fundamentar quando nos diz que o princípio de incerteza na Física apenas pode ser compreendido se articularmos a observação com o sistema operatório de distinções do observador e nada mais.

No caso dos sistemas vivos algo de semelhante pode ser verificado e aquilo que há são sistemas estruturalmente determinados num processo de «structural drifting» nos seus nichos ecológicos.

A possibilidade de intersecção entre vários sistemas está sempre em aberto dado o facto de as unidades poderem sempre aumentar a sua complexidade mediante recurso a meios diferentes do meio original no respectivo drift ontogenético. A partir do conceito de drift ontogenético mostra H. Maturana, numa aproximação que recorda os conceitos de polimorfia e policontexturalidade da vida de G. Günther, de que modo se podem suceder «intersecções estruturais» na formação de um indivíduo, constituindo este último uma unidade compósita com condições ontológicas muito variadas.

O drift ontogenético de um indivíduo humano supõe os estratos «vertebrado", "mamífero», "mulher», "médico», etc, mas de tal modo que nesta intersecção são classes de identidade estrutural que se combinam de um modo não-aleatório.

A desintegração de uma dessas classes pode implicar a desintegração do conjunto, mas a desintegração de outras pode não ter esse efeito. É a propósito desta "policontexturalidade» da vida no drift ontogenético que o artigo retoma o conceito de autopoiésis, já conhecido do início de 1980, e o conceito conexo de acoplamento estrutural. 
Se tomarmos em conta ainda o contributo de G. Günther sobre a "policontexturalidade»(20) apercebemo-nos como a visão que parte de uma realidade objectiva independente das descrições dos observadores não só ignora que quando referimos qualquer coisa no mundo objectivo temos de descrever essa coisa fora do referido mundo objectivo, num universo constituído por sinais, signos e símbolos, como ainda se desconhece o facto de estas descrições estarem na maior parte dos casos articuladas com formas de vida plurifocais, na modalidade de um número ilimitado de "contexturas", cuja independência relativa umas em relação às outras é a própria razão de não podermos ter uma visão monolítica da realidade, baseada numa única "contextura», e não ser possível sustentar uma única via pela qual a vida inteligente emergiu da matéria. O construtivismo entendido a partir do projecto poli-contextural de G. Günther traz consigo, portanto, a ideia de realidade pluri-focal e de observação pluri-focal.

O cruzamento dos trabalhos de H. von Foerster, de G. Bateson, de H. Maturana e de G. Günther com a concepção da Lógica da Forma de G. Spencer Brown teve consequências importantes na compreensão do conceito de observação da teoria dos sistemas ${ }^{(21)}$.

(20) Cf. G. Günther, «Life as poly-contexturality» in vordenker.de, February 2004. Num texto de apresentação das suas ideias, muito resumidamente se justificava G. Günther relativamente à "poli-contexturalidade" com as seguintes palavras: Für die klassische Theorie hat alles Irdische und Sinnliche eine einzige metaphysiche Qualität, und es ist insofern mono-kontextural. In andern Worten: seine Rationalität formt ein ontologisches Kontinuum, in dem keine Abbrüche auftreten können. Das Irdische ist qua Irdisches im Prinzip überall gleich zugänglich. (...) Andererseits zeigt sich das Verlassen des klassischen Weltbildes bei Hegel darin an, daß er die beiden Universalkontexturen, die am Anfang seiner Logik stehen, ausdrücklich als vertauschbar erklärt. Sein und Nichts formen kein Rangverbältnis, wie man erwarten könnte, sondern dieser Philosoph der Dialektik erklärt dieselben ausdrücklich als ein Umtauschverbältnis. Wenn nun der dialektische Materialismus postuliert, daß uns die Objektivität der Welt nicht als Kontinuität von Materie gegeben ist, sondern nur in der Vielheit der materiellen Qualitäten, so bedeutet das (...) nicht anderes, als daß die Wirklichkeit nur poly-kontextural begriffen werden kann. (...) Diese Positionswerte definieren unsere Welt als einen poly-contexturalen Wirklichkeitszusammenhang, in dem die Objektivität einer Kontextur einen gleichwertigen Objektivitätanspruch einer anderen ausschließt. Objektive Wirklichkeit ist infolgedessen nicht etwas, was als an sich existierend festgestellt werden kann, sondern was als Resultat eines Deutungsprozesses erscheint, während der klassische Begriff der Realität aller Deutung enthoben ist. (Idem, «Selbstdarstellung im Spiegel Amerikas» in L. Pongratz (Hrsg.), Philosophie in Selbsdarstellungen, Bd. II, Hamburg, 1975, pp. 56-69).

(21) O leitor pode rever um dos resultados mais interessantes do cruzamento destas correntes teóricas com a teoria dos sistemas de N. Luhmann no livro de P. Fuchs, Der Sinn der 
É neste laço que podemos entender por que motivo desde o conceito de observação somos levados até ao conceito de forma e deste até ao 220 conceito de distinção.

A vantagem da abordagem da Lógica da Forma reside em se poder manter as análises do conceito de distinção numa base geral e abstracta, independentemente do âmbito a que se aplica e dos conteúdos.

Partindo daí podemos dar sentido a questões tão gerais como "O que fazemos quando estabelecemos uma distinção?».

A observação é uma actividade que envolve estabelecimento de distinções e basicamente é feita de distinções entrelaçadas.

Supondo um espaço binário elementar, na observação, a distinção gera uma diferença entre dois planos, em que um deles é a referência e o outro o acto de estabelecer a referência. Num sentido muito geral, a observação pode ser reduzida a uma distinção em cujos lados vemos a indicação e o indicado.

Na continuação da teoria dos sistemas por N. Luhmann teve uma especial importância a tradução destes conceitos de forma e de distinção na diferença entre sistema e meio.

A diferença entre sistema e meio tem hoje um alcance que a torna útil para esclarecer o próprio conceito de observação.

A linha divisória que separa sistema de meio pode ser descrita de um modo formal como uma linha que separa auto-referência e hetero-referência. O meio ambiente é para o sistema o horizonte das suas possibilidades de processamento de informação. Mas a referência a um meio ambiente por parte de um sistema só é possível de um modo condicional, ou seja, na medida em que o dualismo da auto- e da hetero-referência for e se mantiver uma condição para regular as próprias operações do sistema. A única permanência é a permanência do próprio movimento, que opõe auto- e hetero-referência.

Beobachtung. Begriffliche Untersuchungen, Weilerswist, 2004. 
Do ponto de vista desta correlação rigorosamente estabelecida entre as operações do sistema e o meio ambiente, este último está sempre numa condição de indeterminação e é sempre expansível, na medida em que assim o exigir a condição momentânea da auto-reprodução do sistema. É por isso que N. Luhmann considera que o meio ambiente deve ser pensado na mesma linha em que se insere o conceito husserliano de "horizonte».

No entanto, a referência ao horizonte não pode ser nunca entendida num esquema semelhante ao da referência a coisas.

«Só se vê o que se pode ver», o que significa que a doação de um horizonte está tecida pela auto-referência do sistema e pelos critérios de relevância que o sistema traçou para se autonomizar em relação ao meio.

A formulação de Wittgenstein pode aqui ser glosada e indefinidamente sujeita a re-entradas.

- Ele não pode ver o que ele não pode ver.

- Ele não pode ver, que ele não pode ver, o que ele não pode ver.

A cegueira reflecte a própria auto-referencialidade do sistema na relação com o meio ambiente. Os paradoxos da auto-referência não podem ser excluídos ou totalmente eliminados, como havia visto G. Bateson, pois eles são a garantia da própria articulação entre auto- e hetero-referência.

Uma das respostas tradicionais aos problemas da auto-referência encontra-se na obra de B. Russell e na sua tese da multiplicidade dos níveis de linguagem que deve ser tomada em conta para fixar determinados níveis como «linguagem objecto» e outros como «metalinguagem», numa hierarquia de níveis.

Todavia, para estabelecer a hierarquia de níveis ficamos sem critérios muito claros, argumenta N. Luhmann, e ficamos sem resposta para as violações mais flagrantes do respeito pela hierarquia, que constantemente ocorrem na comunicação, como sublinhara G. Bateson.

Uma proposta diferente da "teoria dos tipos» pode esperar-se da contribuição de H. von Foerster e da sua "cibernética de segundo grau", a que recorre também N. Luhmann. 
A observação de segundo grau, que é indispensável para o auto-encerramento sistémico frente ao meio, começa pela detecção da auto-referência e com a clarificação da linha divisória que com base nela se originou, o que torna a auto-referência num dado positivo e não negativo.

Ao se constituir como observação de observadores, a observação de segundo grau realiza a transformação daquilo que para o sistema era o carácter "dado por garantido" do seu meio, o seu "nicho ecológico» indiscutível, o que chamamos na vida quotidiana a "realidade», o ser objectivo, etc., naquilo que é contingente e relativo, porque agora estão disponíveis as condições operatórias em que aquela realidade inicialmente «dada por garantida» tinha sido gerada. Ao nível da cibernética de segunda ordem e da observação de segundo grau é possível compreender de que modo um sistema constitui o seu meio graças à possibilidade que ele tem de contar com as suas próprias operações para continuar a operar no meio, sempre de uma forma auto-referencial ${ }^{(22)}$.

Os dois lados da distinção entre auto- e hetero-referência não possuem o mesmo valor nem pertencem ao mesmo plano. A diferença entre indicador e indicado é a mesma que temos presente quando objectivamos a diferença entre campo visual e olho.

Entre estes dois temos uma diferença de valor, pois estamos perante elementos diferentes quando nos referimos ao olho e ao campo visual. Assim, a distinção é sempre distinção redobrada, dupla distinção ou distinção assimétrica. H. Maturana escreveu a propósito que «o que é visto não tem nunca o mesmo significado do ver».

$\mathrm{Na}$ medida em que envolve um processo de génese interna toda a distinção entre observador e região semântica de referência é uma auto-divisão. Por meio desta vemos surgir uma distinção ou "marcação de uma diferença».

(22) As observações de H. von Foerster sobre o funcionamento do sistema nervoso com apoio na ilustração do Toro são concludentes a respeito da inevitabilidade da auto-referência e dos mecanismos de feed-back, que contam com as próprias operações anteriores do organismo, na cognição e na acção nos organismos complexos, como o Homem. Cf. «Über das Konstruiren von Wirklichkeiten" In Idem, Wissen und Gewissen, op. cit., pp. 46-47. 
Este carácter da dupla distinção advém à própria distinção em virtude de esta se poder tomar a si própria como tema de si mesma para ulteriores distinções e observações, em que um e um só dos lados da distinção é responsável pela replicação das duas faces iniciais da distinção, como é 223 possível concluir de algumas instruções do cálculo da forma da Lógica da Forma de G. Spencer Brown.

É do lado da visão e não do lado do "Visto» que é possível esperar a replicação da distinção nas suas duas faces. É esta característica da observação como distinção que faz com que tenhamos de separar na distinção/observação entre aquela face que condiciona o movimento e a outra que nos surge como "região semântica» da primeira. A face que condiciona o movimento é o aspecto operatório da distinção/observação, quer dizer, o lado que assegura a "re-entrada da forma na forma" ou a re-entrada da distinção dentro dela mesma.

É aqui que podemos voltar à questão da diferença entre actualidade e potencialidade. Ao focarmos agora esta característica de toda a distinção/ /observação, que é a re-entrada, apercebemo-nos que, graças a ela, a actualidade, ou o que temos chamado "realidade» em virtude de um velho hábito, perde progressivamente o valor de "coisa» diante dos olhos que ainda agora lhe garantíamos mediante o nosso olhar polarizado pela evidência directa, para em vez disso a nossa atenção se focar na unidade da distinção. O visado deixa de ser a coisa para passar a ser a própria unidade entre visão e ser visto. A efectivação desta re-entrada implica a transformação modal correspondente.

A transformação modal a que me estou a referir representa aqui a rotação de quatro eixos em simultâneo.

A re-entrada da observação na observação permite ver como a observação de primeiro grau é fruto de uma individuação do indicado e do indicador e como não é possível individuar o indicado sem individuar, também, o indicador. O conceito adequado aqui é o de uma co-individuação, em que ambas as faces da distinção resultam de uma única contingência. 


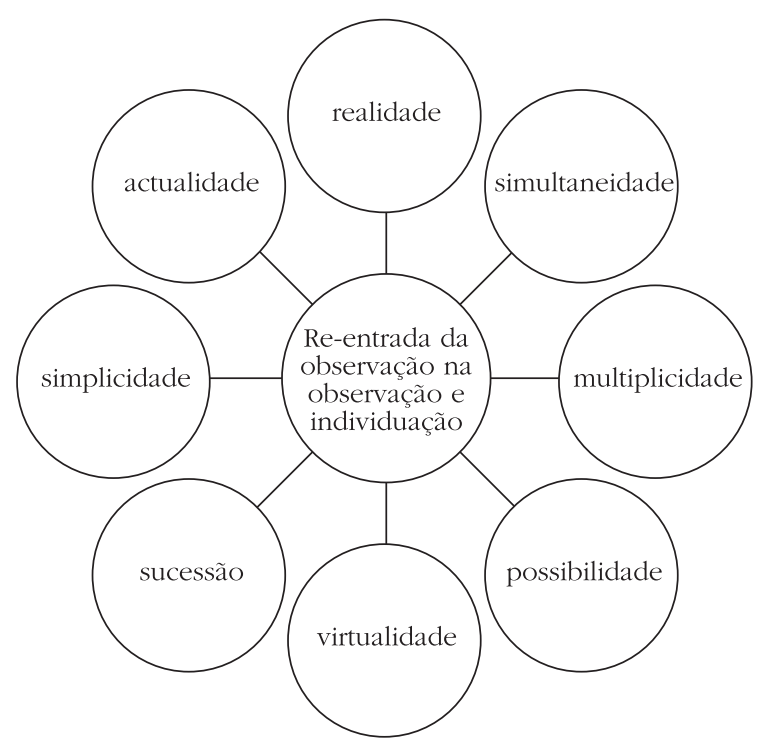

Figura 1 - estrutura radial da re-entrada da observação na observação e da individuação como processo dinâmico.

A partir daqui podemos sumariar algumas ideias fundamentais.

1. Com a re-entrada da observação na observação revela-se o carácter contingente da observação de primeiro grau e da distinção entre visão e "ser visto" que aí se organizou e o carácter co-individuado da indicação e do indicado;

2. O que a tradição ontológica chamou individuação de entidades ou simplesmente o ente não se pode caracterizar como uma imagem mental que associamos a coisas fora do espírito dotadas destas e daquelas propriedades, mas é o efeito passageiro de uma selecção que ocorre num movimento incessante de reversão em que participam os quatro eixos assinalados.

O real aparece-nos, deste ponto de vista, como um processo dinâmico interior às observações de auto-replicação de uma forma ou distinção primitivas. 
Simplicidade e multiplicidade, realidade e virtualidade, existência e possibilidade, simultaneidade e tempo cruzam-se no movimento replicativo do real pelo encadeamento das observações e por meio das respectivas modificações modais.

Uma tal visão é possível na medida em que supusermos que a unidade entre observação e realidade é o conceito de indivíduo. Mas, dada esta significação de indivíduo, este último já não representa uma coisa ou um agregado de predicados, independentes de um observador, mas está sempre associado a um processo de co-individuação do indicador e do indicado, nas duas faces da distinção e implicando os quatro eixos em que se desenvolve a selecção da "realidade».

Uma teoria da individuação depende do esclarecimento do mecanismo da rotação dos quatro eixos, com os respectivos pares diferenciais. É, num certo sentido, uma teoria do real e do possível.

A partir daqui assinala-se à investigação ontológica um novo rumo. Não já aquele que procurou inspirar-se na pretensa originalidade do Ser, mas sim a via que busca no dinamismo interno da individuação e no processo dos seus eixos o nó que impede a separação entre o real e a sua reflexão, graças à indefinida replicação interna das observações do mundo, desde aquilo que, por presunção redutora, se chamar a mais básica distinção até à complexidade poli-contectural.

Uma Ontologia com este sentido não seria já dissociável de uma teoria da reflexão e esta última também já não pode entender-se apenas como uma teoria do sujeito, e do sujeito humano em particular, mas terá de se desdobrar como teoria universal das distinções com valor operatório. Entre estas últimas a distinção entre consciência humana e mundo é apenas um caso, que ganhou o prestígio que lhe continuamos a atribuir em virtude da evolução especial da espécie humana e da sua capacidade de gerar as distinções com que cartografa os pontos de referência no seu próprio drifting. 
Para além de ter de contar com o apoio de uma adequada concepção das observações de primeira e de enésima ordem, a teoria da individuação supõe uma dinâmica ou energética, na medida em que tem de se defrontrar com a permanente oscilação interna dos membros das oposições binárias na direcção uns dos outros, como acontece na constante passagem da potencialidade na actualidade e vice-versa, que constatamos na forma mais rudimentar da estrutura temporal da consciência humana.

Mas ainda tem de explicar, segundo o mesmo dinamismo, essa inacabável agitação do real que em vez de se exaurir na primeira e edénica observação das suas diferenças mais rudimentares se precipita, ao contrário, e sempre novamente, no abismo de uma indefinida replicação das distinções em outras distinções e em que a garantia da sua individuação é paga pela sua abertura a uma individuação mais complexa. 


\section{BibliografiA}

D. Baecker, «Kybernetik zweiter Ordnung» in H. V. Foerster, Wissen und Gewissen.Versuch einer Brücke, Frankfurt/M., 1993.

Idem, "Die Theorieform des Systems" in Idem, Wozu Systeme, Berlin, 2002, pp. 83-110.

Idem (Hrsg.), Kalkül der Form, Frankfurt/M., 1993.

G. Bateson, "The Position of Humor in Human Communication" in C. Pias (Hrsg.), Cybernetics Kybernetik - The Macy Conferences 1946-1953, vol. 1, Zürich/Berlin, 2003, pp. 541-574.

H. v. Foerster, "Quantum Mechanical Theory of Memory» in C. Pias (Hrsg.), Cybernetics - Kybernetik - The Macy Conferences 1946-1953, o. c., pp. 98-121.

Idem, Wissen und Gewissen. Versuch einer Brücke, Frankfurt/M., 1993

P. Fuchs, Der Sinn der Beobachtung. Begriffliche Untersuchungen, Weilerswist, 2004.

P. Fuchs / M. Wörz, Die Reise nach Wladiwostok, Weil der Stadt - Stuttgart, 2004.

E. von Glasersfeld (Hrsg.), Radikaler Konstruktivismus. Ideen, Ergebnisse, Probleme, Frankfurt/ M., 1997.

E. Goldammer, «Eine polycontexturelle Systemtheorie und deren konsequenzen» in Vordenker - Webforum für Innovatives in Wissenschaft, Wirtschaft und Kultur - www.vordenker.de

H. Gumin / H. Meier (Hrsg.), Einführung in den Konstruktivismus, München, $2002^{6}$.

G. Günther, «Negation and contexture» [Manuscript - Staatsbibliotek Berlin Nachl. 196 (Gotthard Günther) Mp 266].

Idem, Idee und Grundriß einer nicht-Aristotelischen Logik, Hamburg, $1991^{3}$.

Idem, Beiträge zur Grundlegung einer operationsfähigen Dialektik, 3 Bd., Hamburg, 1976 e ss.

Idem, "Als Wille verhält der Geist sich praktisch" in Hegel-Jabrbuch, 1977-1978, pp. 55-59.

Idem, "Cognition and Volition - Erkennen und Wollen. Ein Beitrag zu einer kybernetischen Theorie der Subjektivität" in Vordenker - Webforum für Innovatives in Wissenschaft, Wirtschaft und Kultur - www.vordenker.de

Idem, "Life as Poly-contexturality» in H. Fahrenbach (Hrsg.), Wirklichkeit und Reflexion. Festschrift für Walter Schulz, Pfullingen, 1973, pp. 187-210. Reed. in Vordenker - Webforum für Innovatives in Wissenschaft, Wirtschaft und Kultur - www.vordenker.de

Idem, "A new approach to the logical theory of Living Systems" in Vordenker - Webforum für Innovatives in Wissenschaft, Wirtschaft und Kultur - www.vordenker.de

Idem, «Identität, Gegenidentität und negativsprache» in Vordenker - Webforum für Innovatives in Wissenschaft, Wirtschaft und Kultur - www.vordenker.de

Idem, "Der Tod des Idealismus und die letzte Mythologie» unveröffentlichtes Manuskript im Besitz der Staatsbibliothek Preußischer Kulturbesitz, Berlin. Versão editada por R. Kaehr para uso interno do ICS in http://www.thinkartlab.com/pkl/tod-ideal.htm 
Idem, "Selbstdarstellung im Spiegel Amerikas" in L. Pongratz (Hrsg.), Philosophie in Selbsdarstellungen, Bd. II, Hamburg, 1975, pp. 56-69.

R. Kaehr, "Kompass. Expositionen und Programmatische Hinweise zur weiteren Lektüre der Schriften Gotthard Günthers» in Ernst Kotzmann (Hg.), Gotthard Günther - Technik, Logik, Technologie, München-Wien, 1994, pp. 81-125.

Idem, "Zur Logik der second order cybernetics. Von den "Laws der Form» zur Logik der Reflexionsform" in Kybernetik und Systemtheorie - Wissenschaftsgebiet der Zukunft? Dresdener Symposium 91 - Fachbericht des Instituts für Kybernetic und Systemtheorie ICS. Reed. www. vordenker.de Aug 14, 1999.

B. Longuenesse, Hegel et la Critique de la Métaphysique, Paris, 1981.

N. Luhmann, Die Kunst der Gesellschaft, Frankfurt/M., 1995.

Idem, "Das Medium der Kunst” in Idem, Aufsätze und Reden, Stuttgart, 2001, pp. 198-217.

Idem, Die Gesellschaft der Gesellschaft, Frankfurt/M., 1997, 2 Bände.

Idem, Ökologische Kommunikation, Opladen, $1990^{3}$.

Idem, "Die Paradoxie der Form» in D. Baecker (Hrsg.), Kalkül der Form, op. cit., pp. 197-212.

H. Maturana, "The Biological Foundations of Self Counsciousness and the Physical Domain of Existence» in AA. VV., Beobachter. Konvergenz der Erkenntnistheorien? München, 1990, pp. 47-118.

Idem, La Realidad: objectiva o construida?, 2 vols., Barcelona, 1995.

Idem, Was ist Erkennen. Mit dem Kolloquium "Systemtheorie und Zukunft» (trans.), München-Zürich, 1996.

W. S. Mc.Culloch, "Toward some Circuitry of ethical Robots or an observational Science of the Genesis of Social Evaluation in the Mind-like Behavior of Artifacts» $13^{\text {th }}$ Conference on Science, Philosophy, and Religion, New York, Sept. 1952. Reed. www.vordenker.de Feb $10,2001$.

A. Müller / K. H. Müller / F. Stadler (Hrsg.), Konstruktivismus und Kognitionswissenschaft. Kulturelle Wurzeln und Ergebnisse. Heinz von Foerster gewidmet, Wien - New York, 2001.

C. Pias (Hrsg.), Cybernetics - Kybernetik. The Macy-Conferences 1946-1953. Transactions/ Protokolle, 2 Bd., Zürich, Berlin, 2003.

B. Poerksen, The Certainty of Uncertainty. Dialogues introducing Constructivism, (trad), Exeter, 2004 .

Siegfried J. Schmidt (Hrsg.), Der Diskurs des Radikalen Konstruktivismus, Frankfurt / M., 1996.

L. Segal, The Dream of Reality - Heinz von Foerster's Constructivism, New York, 2001.

G. Spencer-Brown, Laws of Form/Gesetze der Form, Internationale Ausgabe, Lübeck, 1997.

P. Watzlawick, Die erfundene Wirklichkeit - Wie wissen wir, was wir zu wissen glauben? Beiträge zum Konstruktivismus, München, $2002^{15}$

F. Varela / E. Thompson / E. Rosch, Der mittlere Weg der Erkenntnis. Der Brückenschlag zwischen wissenschaftlicher Theorie und menschlicher Erfabrung, (trad.), Bern, München, Wien, 1991.

P. Watzlawick - J. B. Bavelas - D. D. Jackson, Pragmatics of human Communication. A Study of interactional Patterns, Pathologies, and Paradoxes, New York - London, 1967. 



\section{Série}

\section{Documentos}

Imprensa da Universidade de Coimbra

Coimbra University Press

2007

- U

C • 